\title{
Accurate Direct Measures Are Required to Validate Derived Measures
}

\author{
Luis Pereira-da-Silva ${ }^{a, b}$ Daniel Virella ${ }^{a, b}$ \\ ${ }^{a}$ Neonatal Intensive Care Unit, Hospital de Dona Estefânia, and besearch Unit, Centro Hospitalar de \\ Lisboa Central, Lisbon, Portugal
}

Dear Sir,

We have read the interesting study by Ferguson et al. [1] who aimed at determining which among 3 commonly used indexes based on body weight and length best measures body proportionality in preterm infants. Sex-specific correlations were examined and stratified according to gestational age, and body proportionality measures were plotted against body length.

We would like to share our concerns on the method used to measure body length, an essential variable in this analysis. The study was based on original data from the Pediatrix Medical Group cross-sectional birth data of 391,681 infants collected from 248 US hospitals [2]. The method used by neonatologists and/or neonatal nurse practitioners for measuring body length was not described in this study [2]. On the other hand, in the study on intrauterine growth curves based on data from the same database, Olsen et al. [3] specified that tapes were used for measuring body length [3]. In these publications $[2,3]$, no other detail is specified regarding the method used for the measurement, specifically if 2 collaborators had always participated in the measurements. The inclusion of potentially inaccurate birth length measurements from the Olsen charts in Fenton's 2013 metaanalysis was criticized previously [4]. In brief, concerns were addressed on the potential inaccuracy of neonatal crown-heel length measurements due to the reluctance of the observer to provoke discomfort when extending the lower limbs against the physiological flexor posture of the neonate [5] and the use of inappropriate examination procedures [6] and instruments such as a measuring tape [7].

\section{References}

1 Ferguson AN, Grabich SC, Olsen IE, Cantrell R, Clark RH, Ballew WN, Chou J, Lawson ML: $\mathrm{BMI}$ is a better body proportionality measure than the ponderal index and weight-forlength for preterm infants. Neonatology 2018; 113:108-116.

2 Thomas P, Peabody J, Turnier V, Clark RH: A new look at intrauterine growth and the impact of race, altitude, and gender. Pediatrics 2000;106:E21.
We reinforce our concerns that inaccurate measurements of crown-heel length may have influenced the correlations between the derived indexes, which are the backbone of the presented analysis. Inaccurate crownheel length, if squared (body mass index), magnifies the error of the index in which it is included, while losing the ability to differentiate overestimation from underestimation; when cubed (ponderal index), while the inaccuracy of the length measurement is further magnified, it still differentiates overestimation from underestimation.

In spite of the possibility that the final recommendation of Ferguson et al. [1] may be correct, the required strong evidence can only be achieved if the accuracy of crown-heel length measurements in large cohorts - similar to the accuracy for weight - is more easily attained [7].
3 Olsen IE, Groveman SA, Lawson ML, Clark $\mathrm{RH}$, Zemel BS: New intrauterine growth curves based on United States data. Pediatrics 2010;125:e214-e224.

4 Pereira-da-Silva L, Virella D: Is intrauterine growth appropriate to monitor postnatal growth of preterm neonates? BMC Pediatr 2014;14:14.

5 Pereira-da-Silva L, Bergmans KIM, van Kerkhoven LAS, Leal F, Virella D, Videira-Amaral JM: Reducing discomfort while measuring crown-heel length in neonates. Acta Paediatr 2006;95:742-746.
6 Wood AJ, Raynes-Greenow CH, Carberry AE, Jeffery HE: Neonatal length inaccuracies in clinical practice and related percentile discrepancies detected by a simple length-board. J Paediatr Child Health 2013;49:199-203.

7 Johnson TS, Engstrom JL, Gelhar DK: Intraand interexaminer reliability of anthropometric measurements of term infants. J Pediatr Gastroenterol Nutr 1997;24:497-505.

\section{KARGER}

두 2018 S. Karger AG, Basel

E-Mail karger@karger.com

www.karger.com/neo
Prof. Luis Pereira-da-Silva

Hospital de Dona Estefânia

Centro Hospitalar de Lisboa Central

Rua Jacinta Marto, PT-1169-045 Lisbon (Portugal)

E-Mail l.pereira.silva @ chlc.min-saude.pt 